\title{
Second Language Acquisition in the Target Language Environment based on the Theory of Affordances
}

\author{
Xiaoyan Zeng \\ Overseas Education College \\ Xiamen University \\ Xiamen, China
}

\author{
Tongtao Zheng* \\ Overseas Education College \\ Xiamen University \\ Xiamen, China \\ *Corresponding author
}

\begin{abstract}
The Traditional Chinese as a second language teaching put emphasis on classroom teaching and pay little attention to extra-curricular learning. Besides, the existing theories of second language acquisition fail to account for second language learners' effective acquisition in the target language environment. Therefore, on the basis of the theory of Affordances, from the perspective of linguistics, the paper tries to develop the theory of Affordances from the two aspects of active learning ability of selfexploration and language niche. In addition, the developed theory of Affordances is practiced in the second language acquisition in the target language environment. The paper illuminates the effectiveness of second language acquisition in the target language and expounds the theory' representation and functions in second language acquisition in the target language.
\end{abstract}

Keywords-second language acquisition; the theory of affordances; language niche; active learning ability based on independent exploration

\section{INTRODUCTION}

In the field of Applied Linguistics, the experience of successful learners began to attract scholars' attention. As we all know, many successful language learners or teachers engaging language teaching and research all agree that learning knowledge, taking part in activities and experiencing life in the target language country can facilitate second language learners' grasping the second language.

Classroom teaching and extra-curricular learning depend on and interact with each other. Long' empirical investigation confirmed that classroom teaching can accelerate the speed of language acquisition. [1] In fact, the emphasis on classroom teaching and extracurricular learning vary from different scholars. For example, X.Y., Zeng, a Chinese scholar, summarized the theory of Chinese vocabulary teaching to foreigners, which is divided into four main areas: (1) Grammar research-based teaching, such as methods of morpheme teaching, Chinese Character as the unit, Chinese $\mathrm{Ci}$ (similar to a word in English but not the same all the time) as the unit, the theory of chunks, and so on; (2) Environment-Based teaching, such as contextual theory; (3) Cognitive model-based teaching, such as the theory of internalized language and the metaphor; 4 . Student-oriented teaching, such as the theory of cognitive load [2]. The common concerns of the above four areas are classroom teaching, Chinese vocabulary itself, and students' effective cognition in the processes of classroom learning. Although the student-oriented teaching begins to take notice of learning' subject-----learners, its' focus is not on extra-curricular learning, but on improving the efficiency of classroom teaching and serving vocabulary teaching in the classroom from different aspects. Second language acquisition in the target language environment is very effective. However, no theories of second language acquisition can give a satisfactory explanation.

This paper attempts to study second language acquisition in the target language environment based on the theory of Affordances. Perceptual psychologist Gibson proposed the theory of Affordances [3], which, emphasized in the natural sciences, is seldom applied to the Humanities and Social Sciences. Recently, some few researchers began to focus on the Affordances theory' application in language teaching or second language acquisition. For example, Larsen-Freeman [4] and Van Lier [5] initiated the study of second language acquisition as a complex system and ecological phenomena. In the process of second language acquisition, they believe sensory, cognitive, emotional and other factors do not exist in isolation, but are linked with each other. The research perspective of ecological approaches has transformed second language acquisition's focus from the language structure's learning to a social practice of language as a symbol. Leily Ziglari introduced the theory of affordance from the ecological perspective [6]. In his view, teachers should understand what learners need, and provide suitable teaching content based on the needs of learners, or provide technical and multimedia supports. Paiva, V. L. M. O. seek the Affordances of extra-curricular learning by adopting the ecological point of view [7]. He described in detail how to develop learners' language competence outside classroom teaching. However, focusing on the Affordances theory's application, most of the above studies failed to develop the theory and to explore its representation and functions. Besides, the above studies did not explore second language acquisition in the target language environment from the perspective of the Affordances theory. Therefore, the paper tries to apply and develop the theory of Affordances proposed by Gibson in second language acquisition.

\section{THE DEVELOPMENT OF THE AFFORDANCES THEORY}

The existing Affordances theory cannot solve the problems in the second language acquisition in the target language. Therefore, based on the traditional understanding of the Affordances theory, this paper tries to develop the theory of Affordances from the two important perspectives of active learning ability of self-exploration and language niche. 


\section{A. Active Learning Ability of Self-exploration}

"Affordances of the environment are what it offers the animal, what it provides or furnishes, either for good or ill" and "refers to both the environment and the animal." [8] Gibson pointed out that the animal and the environment has a complementary and symbiotic relationship. "Affordances are properties of the animal-environment system, that is, that they are emergent properties that do not in here in either the environment or the animal"[9]. From this definition, the Affordances are neither properties of the animal nor properties of the environment, but they are emergent in the interaction of the individual and the environment. Besides, "Affordances are relations between the abilities of organisms and features of the environment."[10][11] In this statement, it is the relationship that is emphasized.

Van Lier believes that the Affordances is a property of the environment, which means it has a relationship with the activity of the environment and the perception of the body. [12] Based on the ecological point, Van Lier defends that "from an ecological perspective, the learner is immersed in an environment full of potential meanings. These meanings are available gradually as the learner acts within and with the environment."[13] Van Lier summarizes different definitions of the Affordances. [14] Van Lier describes two definitions of the Affordances: (1) "Affordances consist in the opportunities for interaction that things in the environment possess relative to sensoriomotor capacities of the animal." (2) "demands and requirements, opportunities and limitations, rejections and invitations, enablements and constraints."[15] It is an improvement on Shotter and Newson's definitions.

Van Lier added two definitions: (1) "Affordances are relations of possibility between animals and their environments"; (2) Forrester in the context of language [16], as "Immediately recognizable projections, predictions and perceived consequences of making this (and not that) utterance at any given time."[17]

In summary, scholars explained and applied the theory of Affordances from different perspectives. Their views can be sorted into two: the Affordance is a special property of the environment; the Affordances exist in the relationship between organisms and the environment. Agreeing with the second point of view, we believe that the core of the Affordances theory is learners' active learning ability of self-exploration.

\section{B. Language Niche}

Because of learners' different learning goals, the traditional theory of Affordances cannot give a peculiar explanation about language environment characterized with salience. Language Niche is a typical affordance, targeting for learners with a special need for language learning. The relationship between Language Niche and the Affordances is comprising and being comprised.

In the ecology, ecology niche is an important concept, and scholars give different definitions from different perspectives. For example, Gibson points that "an ecology niche is a kind of affordance for special animals. Animals with different abilities may have something in common in the physical, but will never have an overlapped ecology niche."[18] Gibson gives a definition that "the niche implies a kind of animal, and the animal implies a kind of niche"[19]. In the Dictionary of ecology, the niche is defined as "time position, spatial location and function position of a species associated with other species in the ecosystems and communities” [20]. W.X., Lin believes that "a niche refers to occupied position by each species in space and time in the community and the functional relationship and the function itself of related species. In other words, the niche is a related position of a species with other species within the community, which is used to summarize how species live in the ecological environment"[21]. Polechová and Storch distinguish the niche in three different ways: niche as the description of a species' habitat requirements; niche as the ecological function of the species, and niche as species position in a community or the formalization of ecological niche concept. [22]

By observing the language, we find that there are also some phenomena similar to the ecology niche. Therefore, the niche can be linked with language learning. Paiva translates these approaches as niche as an environment mediated by language, niche as a place to act in by using the language, and niche as a language user position in a discourse community respectively. [23]

As the basic existential unit of language acquisition, niche language is characterized with dynamic, open, complexity, adaptability and many other features. In the target language environment, there are different language niches for different learners. Active learning ability of learners can be developed in a particular language niche.

Through training learners' finding out and taking advantage of language niche on purpose, teachers can improve learners' active learning abilities of self-exploration. Language Niche is used to examine both the individual and all the individuals in common. For examining the individual as a learner, Language Niche begins as a chaos, existing in a variety of ways and occasions. It is the frequency of contact that determines highlighted verbal communication occasions. With the constant intersecting and overlapping of occasions each individual contact with and the increased frequency, the common of the individuals as learners will constantly be clearly presented and begin to be kept in order. Therefore, Language Niche can account for changes from in a mess to in order.

All in all, Language Niche refers to learners' related particular time position and spatial location with different communication objects as well as their functional relationship with associated language information resources. In a language niche of special requirements, learners' active learning ability of self-exploration can be developed.

\section{FUNCTIONS AND PROPERTIES OF THE AFFORDANCES THEORY IN THE TARGET LANGUAGE ENVIRONMENT}

In the frame of the Affordances theory, learners are associated with the environment, which can disclose the process of language learning and discriminate learners' individual differences. The functions of the Affordances theory in the target language environment are the providing, perception and acquisition. The properties of the Affordances theory in the target language environment are as follows: to 
provide purposes/motivations for second language learning; to provide different levels of learning opportunities for second language learning; to provide a wide range of interactive occasions for second language acquisition; to provide applicable and particular language learning environment for second language acquisition.

\section{A. The Functions of the Affordances Theory in the Target Language Environment}

The target language environment provides the environment where second language learners learn a second language, and kinds of language niches which have a close link with the learners. Each language niche is not absolutely separated, but interrelated with each other. It is true for the functions of the Affordances theory.

\section{1) The Providing Function of Second Language Acquisition:}

Target language environment provide food, clothing, shelter, and transportation where language communication behavior may happen. Overall, according to needs of learners and functions of interactive objects, the environment will provide anything social, cultural, political, economic, and customs, which can even be refined. For example, the language niche of a bank, where a language learner is doing business, provides the possibilities of technology and education. The providing of education can be explained as the following: in a particular learning environment, having perceived constituent elements in the context (e.g. human, material resources, tools, etc.), learners with a strong community culture learning objective, learn the second language consciously or unconsciously in the interactive process.

By observing how others open an account, deposit and get cash, exchange foreign currency, and open online banking or credit cards in a bank, a new comer learning Chinese in China can construct a cognitive model through acquired language information. The learner can try to activate and use acquired language information when doing the similar business in a bank. Once repeatedly using of the language information reach to a certain frequency of the input or output, those expressions can be totally acquired. Doing business in a bank will involve language Affordances such as financial, educational and technical, which helps learners acquire related financial jargon, expressions and technical operations in the particular language niche-----the bank.

\section{2) The Perception Function of Second Language Acquisition:}

The perception function of the Affordances, based on previous experience, input perceived information by virtue of sensory channels such as the human auditory, visual, tactile. For learners, extracurricular learning in the target language environment is more conducive to developing learners' intercultural communicative competence. "To perceive the world is to co-perceive oneself. The awareness of the world and of one's complementary relations to the world is not separable." [24] In fact, the perception of things is a way of associating ourselves based on our personal identity. For example, as a glass is concerned, a person takes it as a container for drinking water, while another person takes it as flower containers or as candy containers. In the world of the language, similar examples will occur. As a fragment of sounds is concerned, without reading words, a musician may take it as a song or some beautiful music for enjoying, or can distinguish these sounds from different instruments; A linguist may be very sensitive to its producing way; Sensitive to pronunciations, a language learner can unconsciously discriminate similar phonemes from the sounds to those in its native language. The process of learning the language is just like staying in the forest, where every language learners has results of perception associated with their own interests. e.g. It is hares that the hunter sees; it is forest-walks that lovers see; it is trees that the ranger sees; it is berries or fruits that the hungry person sees. In short, language learners with different abilities may be in the same locale, but will never be in an overlapped language niche.

\section{3) The Acquisition Function of Second Language Acquisition:}

TABLE I. TABLE 1 SECOND LANGUAGE ACQUISITION OF TRANSACTING BUSINESS AT THE BANK COUNTER

\begin{tabular}{|c|c|c|}
\hline \multirow{4}{*}{$\begin{array}{l}\text { Withdraw } \\
\text { al at a } \\
\text { bank } \\
\text { counter }\end{array}$} & A Bank clerk & A language learner \\
\hline & $\begin{array}{l}\text { Excuse me, what can I do for you? } \\
\text { (Polite Chinese: Qingwen, Nin } \\
\text { banli shenme yewu? /Impolite } \\
\text { Chinese: Banli shenme yewu?) }\end{array}$ & $\begin{array}{l}\text { I'd like to withdraw } \\
\text { (Polite Chinese: Wo } \\
\text { xiang qu qian. /Impolite } \\
\text { Chinese: Qu qian.) }\end{array}$ \\
\hline & $\begin{array}{l}\text { Excuse me, how much would you } \\
\text { like to withdraw? (Polite Chinese: } \\
\text { Qingwen, nin xiang qu duoshao } \\
\text { qian? /Impolite Chinese: Qu } \\
\text { duoshao?) }\end{array}$ & $\begin{array}{l}\text { I'd like to withdraw } \\
1000 \text { Yuan (Polite } \\
\text { Chinese: Wo xiang qu } \\
\text { yiqian yuan. / impolite } \\
\text { Chinese:Yiqian yuan } \\
\text { ba.) }\end{array}$ \\
\hline & $\begin{array}{l}\text { Please keep your cash, see you } \\
\text { next time. (Polite Chinese: Qing } \\
\text { shouhao nin de xianjin, man zou. } \\
\text { /Impolite Chinese: Keyi le. }\end{array}$ & $\begin{array}{l}\text { Thank you. (Polite } \\
\text { Chinese: Xiexie nin. } \\
\text { /Impolite Chinese: O!) }\end{array}$ \\
\hline
\end{tabular}

The acquisition function means that language learners, according to their own needs, acquire language and culture from relevant language niches. When transacting business at the bank teller, a language learner interacts with the clerk by way of language communication. If the clerk, with a smile, utter politely and slowly, the language learner will answer more politely and pleasantly. Or else, if the clerk with a cold faces, articulate rudely and quickly, the language learner as a customer would respond impolitely and unwillingly. This suggests expressions and behaviors of the clerk have a great and immediate impact on the language learners' second language acquisition. As shown in Table I, which shows that a language learner makes an interactive conversation with the clerk by receiving language information mainly through the auditory system. Language learners should be encouraged to obtain as many language niches as possible, as shown in Table II: 
TABLE II. SECOND LANGUAGE ACQUISITION WHEN DOING BUSINESS AT A BANK COUNTER

\begin{tabular}{|c|l|l|}
\hline & \multicolumn{1}{|c|}{ An ATM } & A language learner \\
\cline { 2 - 4 } & $\begin{array}{l}\text { Dear customers, Hello, you have entered } \\
\text { the monitored area, please take good care } \\
\text { of your bank card and keep your cash safe, } \\
\text { Withdra case of theft and robbery of various } \\
\text { wal at an } \\
\text { ATM }\end{array}$ & $\begin{array}{l}\text { input information } \\
\text { through the auditory } \\
\text { system }\end{array}$ \\
\cline { 2 - 4 } & $\begin{array}{l}\text { RMB, withdraw, transfer, check, enter the } \\
\text { password, the withdrawal amount, confirm, } \\
\text { cancel, continue, return the card, etc. }\end{array}$ & $\begin{array}{l}\text { input information } \\
\text { through the vision } \\
\text { system }\end{array}$ \\
\cline { 2 - 4 } & $\begin{array}{l}\text { Please take out your bank card. Thank you! } \\
\text { See you next time! }\end{array}$ & $\begin{array}{l}\text { input information } \\
\text { through the auditory } \\
\text { system }\end{array}$ \\
\hline
\end{tabular}

Table I and II respectively show that the target language environment provides an environment and content for learners' language acquisition.

The theory of Affordances has the functions of the providing, perception and acquisition, which gives a functional explanation for examining how a language learner acquires a second language in the target language environment.

\section{B. The Properties of the Affordances Theory in Target Language Environment}

1) To Provide Purposes/Motivations for Second Language Learning:

While learning a first language is for the purpose of survival, learning a second language is for two kinds of purposes: for those who stay in the target language country, the purpose is to survive, while for those who stay in their own country, the purpose is to know the culture of the target language country. Based on different learning goals, language learners should obtain suitable language niches conducive to their development. For example, it is for knowing China that the vast majority of learners learn Chinese as a second language. However, knowing China involves the understanding of China's political, cultural, economic and other aspects. With different hobbies and concerns, language learners understand China by way of different ways and channels. Some understand China by touring around China, some by trading, some by academic exchanges, and some by receiving education in China. Needless to say, all these are motivations of learning a language. For language learners who hope to know China by touring, language niches related to tourism are their priorities, such as language niches associated with transportation, catering, and accommodation, while learners hoping to know China by trading, will try to occupy specific language niches related to the financial, banking, customs, taxation, transportation.

In short, in the target language country, language learners with a dream for knowing the country's language and culture, will find it easy to obtain language niches with multi-functions for facilitating their Chinese learning. As a result of strong learning motivations, language learners will actively interact with the surrounding environment, and keep seeking the Affordances which can meet their own learning goals.
2) To Provide Different Levels of Learning Opportunities for Second Language Learning:

Many language niches for learners are offered by the target language environment, where second language learning occurs. Interestingly, these language niches constitute a bigger language environment. For example, in everyday life, language learners are often linked with hotels, banks, shopping malls (supermarkets), railway stations, airports, etc., which can be understood as language niches with different functions. Levels of second language learners' language ability determine different levels of the Affordances, which can be seen at different stages of second language acquisition. The interactive relationship between second language learners in the beginning stage with the environment is considered as preliminary Affordances. Similarly, the interactive relationship between second language learners in the intermediate stage with the environment is considered as intermediate Affordances, and the interactive relationship between second language learners in the advanced stage with the environment as advanced Affordances.

In any case, from the perspective of language ecosystem, language learning environment consists of some language niches which are combined with each other. Making the most of language niches can help language learners fulfill communicative tasks satisfactorily.

3) To Provide a Wide Range of Interactive Occasions for Second Language Acquisition:

TABLE III. A VARIETY OF INTERACTIVE CATEGORIES AND WAYS

\begin{tabular}{|l|l|}
\hline \multicolumn{1}{|c|}{$\begin{array}{c}\text { Interactive } \\
\text { Categories }\end{array}$} & \multicolumn{1}{c|}{ Interactive ways } \\
\hline Purchasing & $\begin{array}{l}\text { buy clothes, buy a car, buy appliances, buy daily } \\
\text { necessities, buy fruits, buy gifts, etc. }\end{array}$ \\
\hline Eating \& drinking & $\begin{array}{l}\text { have a dinner at a restaurant, be as a guest at a } \\
\text { friend's home, treat friends at home, have tea in the } \\
\text { afternoon, etc. }\end{array}$ \\
\hline shelter & rent a room, decorate a room, check in hotels, etc. \\
\hline transportation & by train, by TGV, by taxi, by bus, etc. \\
\hline Visiting a place & $\begin{array}{l}\text { museums, exhibitions, art exhibitions, exhibitions of } \\
\text { handmade works, etc. }\end{array}$ \\
\hline Visiting a person & $\begin{array}{l}\text { be a guest, visit (a teacher / a leader / relatives, etc.), } \\
\text { visit patients, etc. }\end{array}$ \\
\hline chatting & \begin{tabular}{l} 
weather, jobs, life, learning, family, etc. \\
\hline Congratulations \\
birthday, wedding, New Year, education, promotion, \\
etc.
\end{tabular} \\
\hline Tourism & $\begin{array}{l}\text { hiking, climbing, take a cable car, tour around the } \\
\text { monuments, etc. }\end{array}$ \\
\hline arts & $\begin{array}{l}\text { film, dance, music, Beijing opera, Henan opera, } \\
\text { Kunshan opera, drama performances, etc. }\end{array}$ \\
\hline internet & $\begin{array}{l}\text { online shopping, online chat, e-learning, online } \\
\text { entertainment, etc. }\end{array}$ \\
\hline
\end{tabular}

Interaction in language acquisition refers to the relationship between man and the surrounding environment when interacting with each other, which is established mainly on the basis of the target language. A variety of interactive ways and occasions can be seen in the target language environment. Chinese as a second language acquisition can be taken as a good example, as shown in table III.

When arriving at a strange place for the first time, a language learner often has an experience of asking where a toilet, a ticket 
office or a boiler room is. For example, when looking for a toilet, a Chinese language learner can say in Chinese "Qingwen cesuo zai nali?” or "Qingwen XX zai nali?” The interactive relationship in language acquisition can be seen in the following two cases: First, language learners directly receive or use resources provided by the environment; secondly, language learners, according to their own needs, take the initiative to explore language learning resources and create a good language learning environment.

4) To Provide Applicable and Particular Language Learning Environment for Second Language Acquisition:

Language niches provide a wide range of occasions for language learners to meet their own special necessities. Flocking together, two or more native Thai learners often talk in Thai, even making little notice of their Japanese or English native peers around them. In this case, a language learner preferring speaking his or her native language will lose the opportunity to use Chinese to communicate with friends. For the two native Japanese and English learners, it is a language niche for speaking Thai detrimental to their Chinese learning. The two learners have to reestablish a new circle of friends on demand and try to make friends with other foreign students preferring speaking Chinese or Chinese native speakers.

Language learners should be encouraged to occupy as many language niches as possible. For example, when shopping in the supermarket, a language learner can pay attention to listening to broadcasting markdowns or notice of missing person, ask a clerk in the supermarket about preferred commodities, or try to imitate and use similar expressions after having observed how the cashier make a conversation with other customers at the checkout. The core of the Affordances theory is to develop language learners' active learning ability of self-exploration, encouraging learners to pick up the language by virtue of available resources in the environment, or to create language niches conducive to language learning according to their own needs and the objects' functions.

In short, in order to achieve an effective second language acquisition, language learners need to take the initiative to interact with the environment, occupying as many language niches as possible, which were beyond the reach of them in the past.

\section{CONCLUSIONS}

Classroom teaching can neither gather all the Affordances conducive to language learning nor broaden language learners' horizons. Therefore, in classroom teaching, the studentcentered teaching principle should be adhered to, and students' active learning ability of self-exploration should be developed under the guiding of teachers. This paper introduces the three functions of the Affordances theory in the target language environment: the providing, perception and acquisition of second language acquisition, and the four properties of the Affordances theory: to provide purposes/motivations for second language learning; to provide different levels of learning opportunities for second language learning; to provide a wide range of interactive occasions for second language acquisition; to provide applicable and particular language learning environment for second language acquisition.

\section{REFERENCES}

[1] Long,M and Sato,C Classroom foreigner talk discourse: forms and functions of teachers' questions. In Seliger,H and Long, M(eds.) Classroom-oriented research in second language acquisition, Newbury House, Rowley, Mass. 1983, pp. 268-285.

[2] Zeng Xiaoyan \& Zheng Tongtao, Teaching Chinese as a Foreign Language in the Perspective of the Cognitive Load Theory, Journal of Yunnan Normal University (Teaching and Research on Chinese as a Foreign Language Edition), 5, 2014

[3] Gibson, J.J. The Theory of Affordances. In R. Shaw \& J. Bransford (Eds.). Perceiving, Acting, and Knowing: Toward an Ecological Psychology. Hillsdale, NJ: Lawrence Erlbaum. 1977, pp. 67-82.

[4] Larsen-Freeman, D. "Chaos/complexity Science and Second Language Acquisition”,Applied Linguistics, 8 (1997) .

[5] Van Lier, L. From input to affordance: Social-interactive learning from an ecological perspective. In J.P.Lantolf(Ed.), Sociocultural theory and second language learning :Recent advances, Oxford: University Press, 2000, pp. 245-259.

[6] Leily Ziglari.“Affordance an Second Language Acquisition”, Europen Journal of Scientific Research, 23(2008).

[7] Paiva, V. L. M.O. Affordance beyond the classroom. In P. Benson \& H. Reinders(Eds.), Beyond the classroom: The theory and practice of informal language learning and teaching. Palgrave: Macmillan. 2011, pp. 59-57.

[8] Gibson, J.J. The Ecological Approach to Visual Perception. Hillsdale, New Jersey: Lawrence Erlbaum. 1986, pp. 127.

[9] Stoffregen, T. A. "Affordances as Properties of the Animal Environment System”, Ecological Psychology, 15(2003).

[10] Chemero,A. “An Outline of a Theory of Affordances”,Ecological Psychology, 15(2003).

[11] Van Lier, L. From input to affordance: Social-interactive learning from an ecological perspective. In J.P.Lantolf(Ed.), Sociocultural theory and second language learning :Recent advances, Oxford: University Press, 2000, pp. 245-259.

[12] Van Lier, L. From input to affordance: Social-interactive learning from an ecological perspective. In J.P.Lantolf(Ed.), Sociocultural theory and second language learning :Recent advances, Oxford: University Press, 2000, pp. 246.

[13] Van Lier, L. From input to affordance: Social-interactive learning from an ecological perspective. In J.P.Lantolf(Ed.), Sociocultural theory and second language learning :Recent advances, Oxford: University Press, 2000, pp. 253.

[14] Van Lier,L. "The ecology of language learning and classroom Research”, Retrieved May 14 ( 2004 ) , from www.utc.fr/ untele/2004ppt/vanlier_2004.ppt

[15] Van Lier,L.. The ecology and semiotics of language leaning: A sociocultural perspective, Boston: Kluwer Academic Publishers,2004, pp. 91.

[16] Forrester, M. Conversation and Instruction within Apprenticeship: Affordances for Learning, in P. Ainley and H. Rainbird(eds), Apprenticeship: Towards a New Paradigm of Learning. London: Kogan Page. 1999, pp. 86-97.

[17] Van Lier,L.. The ecology and semiotics of language leaning: A sociocultural perspective, Boston: Kluwer Academic Publishers,2004, pp. 91.

[18] Gibson, J.J. The ecological approach to visual perception. Boston: Houghton Mifflin, 1979. Cited in Chemero, A. An Outline of a Theory of Affordances, Ecological Psychology, 15 (2003).

[19] Gibson, J.J. The Ecological Approach to Visual Perception. Hillsdale, New Jersey: Lawrence Erlbaum. 1986, pp. 129.

[20] An Shuqing, et al. The Dictionary of The Ecology, NorthEast Forestry University Publishing House, China, 1994.

[21] Lin Wenxiong, The Ecology(The Second Edition), The Science Publishing House, 2013, pp. 138.

[22] Polechová, J., \& Storch, D. Ecological niche. In S.E. Jorgensen \& B. Fath(Eds.).Encyclopedia of ecology. Oxford: Elsevier, 2008, pp. 10881097.

[23] Paiva, V. L. M.O. Affordance beyond the classroom. In P. Benson \& H. Reinders(Eds.), Beyond the classroom: The theory and practice of informal language learning and teaching. Palgrave: Macmillan. 2011, pp. 59-57. 
